RAMOS, FRANCISCO RÉGIS LOPES. A DANAÇÃO DO OBJETO: 0 MUSEU NO ENSINO DE HISTÓRIA. CHAPECÓ: ARGOS, 2004.

Júnia Sales Pereira*

\title{
APRENDIZAGEM HISTÓRICA COMO PRÁTICA SOCIAL: LIÇÕES POÉTICAS E ÉTICAS EM “A DANAĈ̣̃O DO OBJETO: O MUSEU NO ENSINO DE HISTÓRIA"
}

\begin{abstract}
"Sofri o grave frio dos medos, adoeci. Sei que ninguém soube mais dele. Sou homem, depois desse falimento? Sou o que não foi, o que vai ficar calado. Sei que agora é tarde, e temo abreviar a vida, nos rasos do mundo. Mas, então, ao menos, que, no artigo da morte, peguem em mim, e me depositem também numa canoinha de nada, nessa água, que não pára, de longas beiras: e, eu, rio abaixo, rio a fora, rio adentro - o rio."

(ROSA, Guimarães. A terceira margem do rio. In: Primeiras Estórias.

Rio de Janeiro: Nova Fronteira, 1988, p. 32)
\end{abstract}

A preocupação com a educação em museus é, diria Walter Benjamin, expressão de um tempo saturado de agoras. Uma primeira leitura do texto de Régis Ramos talvez ajude a problematizar essa assertiva. Ao conceber a educação em museus históricos como ato significado pelo presente, evidentemente em diálogo profundo com o passado, Ramos tece instigante reflexão, colocando, em novos termos, antigos anátemas como aqueles que pressupunham o objeto museal como indício passivo e o museu histórico como cenário estático e imutável.

As subjetividades - em situação relacional são componentes essenciais, sob a ótica de Ramos, aos gestos educativos em museus. A antropofagia Regiana - de que também nos fala Mário Chagas no prefácio da obra - é, ao mesmo tempo, endofagia: digestão do objeto museal, parte humana do vivido pelo próprio museu e pelo visitante. Mantendo o movimento endofágico, o texto enuncia a autobiografia profissional de

\footnotetext{
* Doutora em História (UFMG) e Professora Adjunta da Faculdade de Educação da UFMG.E-mail: juniasales@gmail.com
} 
seu autor. $A$ danação do objeto é não somente um convite à reflexão sobre os desafios ao ensino de história em ambientes não-formais de educação, mas é, significativamente, um diário auto-reflexivo e crítico da vida profissional do Professor de História e Diretor do Museu do Ceará.

É convite a pensar nos objetos que estão não somente no circuito da permanência das nações e suas narrativas de eternização, mas também e especialmente naqueles que estão postos ou se põem à margem da produção voltada ao consumo rápido e devorador. E o faz a partir de sua própria experiência Museu do Ceará. Sua proposta de alfabetização de catadores de lixo pelo objeto gerador fundamenta-se nos pressupostos da significação e das teorias da aprendizagem significativa. Há, aqui, sem dúvida, uma contribuição à pesquisa sobre as potencialidades dos objetos no exercício e conquista do letramento. Relatando o desenvolvimento do projeto Patativa, 2003, Ramos nos incita a pensar que a aventura da aprendizagem da escrita e da leitura no ensino da história é potencializada pela diversidade de registros humanos produzidos e apropriados pelos sujeitos em sua vivência e sua prática social. A aprendizagem histórica, assim concebida, é mediada pela experiência de humanização pela qual passa todo sujeito em sua prática social, plena de sensibilidades adquiridas e que se realizam e se capitalizam no cotidiano.

As propostas de Ramos são pertinentes para um tempo de deslocamentos, em que cada vez mais nos havemos com a mobilidade das fronteiras entre o que é objeto cultural musealisável (salvo? eternizado?) e o que será irremediavelmente relegado ao esquecimento. De uma antiga concepção de relíquia - como objeto morto e eterno - a uma concepção que encena a memória em todo o seu poder combativo e ativo - Ramos lança o leitor a deslocamentos teóricos e conceituais em que convergem história, estética, antropologia e educação.

Sua escrita é um desafio à percepção do objeto castrado de sua fecundidade real, posto que suprimido do tempo vivido e de seu lugar e função originais. Nessa medida, $A$ danação do objeto é também uma antropofagia do espaço museal, lugar (des)vestido de sua aura, recolocado em sua condição humanizadora. É provocação essencial: o museu é território do humano - incompleto, perverso e belo. Matéria do humano, é "Uma beleza, uma podridão", como diria Gil.

E o objeto... Como corpo exposto, ex-posto, posto, o objeto museal configura-se como indício não apenas do que se quer preservar em um dado contexto, mas, ao mesmo tempo, é indício de tudo o que se descartou nesse mesmo contexto e que não compareceu à narrativa de sal- 
vaguarda que re-cria o museu para si e para dada sociedade. Seria possível preservar tudo o que há? O fragmento, dessa forma, é não apenas um lastro fragmentário da realidade social-histórica, mas, ambiguamente, um corpo tornado sobrevivente. Ao museu, dessa maneira, comparece uma história indiciária e náufraga, por vezes escrita sob script de uma sociedade que pinçou e elegeu seus próprios ícones, outras vezes como registro do refúgio de um naufrágio sem espectadores. Seria o museu o indício de um naufrágio da história apartada de sua própria humanidade?

Sob a lente de Ramos, o objeto museal é lugar privilegiado onde se marca a história e se enuncia, em carne viva e sem subterfúgios, a violência mesma da vida, sem retoques. Lembrar-se, assim, é também esquecer-se, porque ao sujeito-objeto da lembrança somente resta o ato de esgueirar-se para os cantos, colocar-se à margem da história, senti-la por meio de fragmentos questionáveis e significantes. Afirma-se a carga vivencial que traz aquele objeto à sua própria humanidade. $\mathrm{O}$ museu de Ramos convoca o objeto-sujeito ao valor ético, enfim, expondo-o apartado, narrado, sentido e lembrado como história, também esta uma sobrevivente.

O objeto em estado de danação de que nos fala Régis Ramos e o ensino de história no fio dessa meada - compõe-se das idiossincrasias próprias da dimensão humana de que se fazem as sociedades que descartam, preservam e que não raro deificam seus testemunhos. Seria possível um museu sem deificações?

Inspirando-se na literatura e sorvendo dela suas melhores tonalidades, o autor nos diz da (im)permanência dos objetos museais: deslocados, colocados e locados em um ambiente de guarda e mostra, os objetos encontram-se irremediavelmente desenraizados.

Nessa "terceira margem" o objeto é fenda de uma perda histórica: não está nem mais no circuito mesmo da vida nem tampouco disponível a outros usos a não ser aqueles tipicamente previstos pelo circuito museal.

Um entre-lugar entre o mundo da lembrança e do esquecimento, o museu exerce sua ambígua condição testemunhal. Para lembrar Guimarães Rosa, o museu impõe aos objetos uma natureza apartada de si, funcionando, por isso, também como armadilha ao esquecimento "alguém vai a um museu de relógios para saber as horas?", pergunta-nos o autor.

O texto oferece pistas à aprendizagem da história: demarca nos múltiplos significados produzidos pelos visitantes as razões de convite, 
pelo museu, à compreensão da materialidade da história travestida em objeto. Mas exatamente porque enrodilhado ao objeto museal - em sua dan(ação) - é que o texto incita a pensar nas potencialidades, mas sobretudo nos limites daquela narrativa sobre o museu para as aprendizagens da história. Será possível aprender história em um museu "sem objetos"? Qual é o substrato que faz de um museu um museu de abordagem histórica?

O livro de Ramos, se por um lado expõe e compõe cenários de significação, por outro demarca os limites de sua própria compreensão: será possível a musealização da oralidade, do gesto, do silêncio, do espaço vazio... "matéria" múltipla de que se compõem as memórias e histórias no tempo? Em que medida a razão fundante de toda a concepção de ensino e aprendizagem da história deverá enrodilhar-se fatalmente ao objetosujeito de danação?

A inquietude talvez resida no fato de que todo gesto endofágico é fundamentalmente auto-interpretativo: a aprendizagem histórica, por suposto, é também aprendizagem de humanização, implica ultrapassagem, autodesconstrução, estranhamento. Nossa humanidade histórica, assim compreendida, assenta-se e se realiza, fundamentalmente, na palavra compartilhada: signo transformado em discurso, enunciação interacional. Podemos pensar que algum museu resistirá aos tempos de aprendizagem histórica da "matéria" mesma de que se faz a história? Está a história irremediavelmente aprisionada à materialidade dos dias?

Resta perguntar-se então por que razões permanecem muitos museus históricos a insistir no poder provocativo objetos ou de acervos postos como história acabada. Ramos aposta nas linhas interacionais dessa condição provocativa dos museus. E, nessa medida, seu livro é o início de uma conversa - ainda a ser alongada - sobre a capacidade dos museus de falar e refletir sobre o ensino e a aprendizagem da história. Se o livro nos explica boa parte dessas razões interpretativas que atravessam o museu, ele, contudo, depara-se com as problemáticas para compreensão dos fundamentos da aprendizagem. O que significa aprender história no museu? E em que medida se anunciam outras práticas educativas - diversas, mas não contrapostas à educação escolar - típicas, então, dos ambientes museais de abordagem histórica? Enfim, ainda nos resta interrogar - cumprem os educadores em museus históricos o mesmo papel que os educadores em atuação nos ambientes escolares? Se a resposta à última pergunta, de princípio, pode ser negativa - é o que parece estar nos sugerindo a leitura de $A$ danação do objeto - ainda nos resta cartografar essa 
prática educativa diversa, pouco compreendida, pouco enunciada pelos educadores - aqui e lá.

É curioso então que a relação com o tempo-espaço do vivido tenha sido tão fundamentalmente elucidativa para Ramos. Não se aprende história de um outro tempo-sujeito sem compreender-se em profundidade a história mesma que nos abate/consome. Só se aprende história pela alteridade, mas uma alteridade radical: no contato com o objeto museal também nos invocamos à interrogação de nossos próprios registros materiais: nossa humanidade é testemunhada por meio do objeto ou o objeto é testemunhado por meio de nós mesmos? Qual é a morada dessa danação?

Convido à prática de tantas endofagias de que são capazes o objeto e o museu no ensino de história - em nós. Fiquemos com um trecho de "A terceira margem do Rio", um ensaio sobre os outros lugares nesse cenário de margens que é o museu. Que as penas de Rosa nos levem a pensar nas instigantes mensagens de Ramos, que, diga-se, carrega consigo toda a herança poética e reflexiva dos grandes escritores. Não seria o objeto museal, no sentido de Ramos, aqui numa releitura de Rosa, um ser pleno de agoras: aquele que ora fala, ora se cala numa água de longas beiradas, rio abaixo, rio adentro?

Recebido: $18 / 04 / 08$

Aprovado: 10/05/08

Contato:

Rua Antonio Elias, 19 - casa 01 Centro

Pedro Leopoldo - MG

BRASIL

CEP: 33600-000

E-mail: juniasales@gmail.com 